OPEN ACCESS

Edited by:

Elemer Szabadi,

University of Nottingham,

United Kingdom

Reviewed by:

Michael Schredl,

University of Heidelberg, Germany

Serena Scarpelli,

Sapienza University of Rome, Italy

${ }^{*}$ Correspondence:

Perrine M. Ruby

perrine.ruby@inserm.fr

Specialty section:

This article was submitted to

Sleep Disorders,

a section of the journal

Frontiers in Neurology

Received: 25 October 2019 Accepted: 28 September 2020 Published: 05 November 2020

Citation: Nicolas A and Ruby PM (2020) Dreams, Sleep, and Psychotropic Drugs. Front. Neurol. 11:507495. doi: 10.3389/fneur.2020.507495

\section{Dreams, Sleep, and Psychotropic Drugs}

\author{
Alain Nicolas and Perrine M. Ruby* \\ Lyon Neuroscience Research Center, CNRS UMR 5292 - INSERM U1028 - Lyon 1 University, Lyon, France
}

Over the past 60 years, the impact of psychotropic drugs on dream recall and content has been scarcely explored. A review of the few existing experimental results on the topic leads us to the following conclusions. For antidepressant drugs, in the great majority, they reduce dream recall frequency (DRF), and the improvement of depressive symptoms is associated with an increase of positive emotion in dream content. For sedative psychotropic drugs, their improvement of sleep quality is associated with a reduction of DRF, but the effect on dream content is less clear. Few occurrences of nightmare frequency increase have been reported, with intake of molecules disturbing sleep or with the withdrawal of some psychotropic drugs. Importantly, the impact of psychotropic drugs on rapid eye movement (REM) sleep does not explain DRF modulations. The reduction of intra-sleep awakenings seems to be the parameter explaining best the modulation of DRF by psychotropic drugs. Indeed, molecules that improve sleep continuity by reducing intra-sleep awakenings also reduce the frequency of dream recall, which is coherent with the "arousal-retrieval model" stating that nighttime awakenings enable dreams to be encoded into long-term memory and therefore facilitate dream recall. DRF is nonetheless influenced by several other factors (e.g., interest in dreams, the method of awakening, and personality traits), which may explain a large part of the variability of results observed and cited in this article.

Keywords: sleep, dream recall frequency, dream content, antidepressant, antipsychotic, anxiolytic, dreaming

\section{KEY POINTS}

- Most antidepressants reduce dream recall frequency. Dream content tends to improve in parallel to improvements in symptoms of depression.

- Sedative psychotropic drugs reduce dream recall frequency by improving sleep quality, but their impact on dream content is not well-known.

- The influence of psychotropic drugs on REM sleep does not modify their impact on dream recall frequency.

- Decrease of intra-sleep awakenings due to taking psychotropic drugs is the variable, which most correlates with dream recall frequency.

\section{INTRODUCTION}

Dreaming is an experience shared by everyone; very few people report having never dreamt [e.g., $(1,2)]$. This mysterious and ubiquitous phenomenon is however difficult to investigate with an experimental approach, since researchers can access dreams only indirectly and a posteriori via dream reports possibly truncated by partial memory and transformed by the awake mind (3). 
As a consequence, the definition of dreaming is still under debate $(4,5)$. The following phenomenological one is nonetheless shared and used by numerous dream researchers [e.g., $(2,6,7)]$ : "Dreaming is a spontaneous phenomenon during sleep which is a true phenomenal experience, i.e., it feels as an experience of the waking life (loss of reality testing). It is composed of "virtual" sensory perceptions and of emotions and it can evoke various and complex representations of the setting, characters, objects and circumstances. The dreamer is therefore both the unaware creator of the dream and its conscious observer and often actor" (7). In other words, most of the time dreams are experienced as real, and the dreamer is unaware of being asleep except in the peculiar case of lucid dreaming (8). Importantly, oneiric representations can be bizarre. After awakening, dreams may be recalled due to the recollection-often fleeting-of the dream memory.

Regarding the link between dreaming and neurophysiology, 60 years of debates has been necessary to get rid of the rapid eye movement (REM) sleep hypothesis of dreaming, and it is now acknowledged by a majority of dream researchers, be they neuroscientist or not, that REM sleep is neither necessary nor sufficient to get a dream report and that dream reports can be obtained at the awakening of any sleep stage $(2,7,9-$ 12). It is also now clear that the complexity and story-like characteristics of dream reports are related to sleep stages but also, and even more so, to circadian rhythms leading to more vivid and complex dreams in the morning than in the early night [e.g., (13-15)]. Recent developments have provided strong experimental arguments in favor of the arousal-retrieval model (16), proposing that awakenings when dream content is still in short-term memory are necessary to encode dreams into longterm memory (17-23).

Several studies have investigated the effects of psychotropic drugs on the structure of sleep (24). However, studies testing the impact of these substances on reported dreams are rarer. The objective of this review is to present a synthesis of these two bodies of research.

\section{EFFECTS OF ANTIDEPRESSANTS ON DREAM RECALL}

Although sleep disorders and complaints about dreams and nightmares are common in depressed individuals (whether they are under treatment or not) (25), only few studies have tested at the experimental level the effects of antidepressants on dream recall [see (26), for a review proposing a table with the antidepressant tested and their effect on dreams in depressed and healthy individuals]. We favored data obtained from healthy subjects when such data exist, in order to avoid the confounding factor of depression. Indeed, depressed patients often report less dreams than healthy participants (27-29), and the tone of their dreams is often more negative $(26,30)$.

The effects of antidepressants on the structure of sleep are rather well-documented. Tricyclic antidepressants tend to improve the quality and duration of sleep $(24,31)$, with some being often used to treat chronic insomnia (32). In contrast, most selective serotonin reuptake inhibitor (SSRI) antidepressants reduce the duration of sleep, increase its fragmentation, and present an insomniac profile (33). The great majority of these substances have a significant impact on REM sleep, by extending its latency period and reducing its duration $(34,35)$.

\section{Monoamine Oxidase Inhibitor Antidepressants}

The only monoamine oxidase inhibitor antidepressant (MAOI) for which we have any data is phenelzine. A further limitation is the fact that data are only available for depressed subjects. Landolt et al. demonstrated that depressed patients who were responsive to phenelzine manifest reduction of dream recall, but not those who were unresponsive, although suppression of REM sleep was equivalent in both groups (36). A positive impact of phenelzine treatment on the frequency of nightmares in patients suffering from post-traumatic stress disorder (PTSD) has also been reported (37). Finally, withdrawal, if sudden, seems to provoke a rebound of dream recall essentially comprising nightmares in both patients $(38,39)$ and healthy subjects $(40)$.

\section{Tricyclic Antidepressants}

In healthy subjects, imipramine reduced the frequency of dream recall in at least two studies $(41,42)$. This effect stands in depressed patients, even if less significant. Furthermore, improvement of dream content has been observed in parallel to improved mood (43) but not in all studies (44). As with MAOIs, withdrawal generally engenders an increase in nightmares and negative impressions during dreaming (45).

Clomipramine does not seem to modify much dream activity (46). This is corroborated by Oudiette et al. (47), who found no major effect on dreams in healthy subjects taking clomipramine, other than increased "strangeness" in sleep stage 2 (N2) dream reports and increased length of sleep stage 1 (N1) dream reports. Interestingly, the molecule would be responsible for an increased risk of REM sleep behavior disorder (RBD) according to Hoque and Chesson (48). RBD is a loss of muscle atonia during REM sleep leading to a playing out of the dreamt actions and possibly causing injuries to patients and their entourage (49).

Amitriptyline did not cause a change in dream activity in healthy volunteers, even after prolonged administration, in the few studies that used a reliable method for collecting dreamrelated data $(46,50)$. Similar results were found in depressed patients (46). With the use of an unstructured questionnaire, perturbation in dreams was detected after withdrawal, but most of the patients also demonstrated signs of relapse into depression (51).

Trimipramine is a different kind of tricyclic antidepressant, as it is the only one in its category that does not provoke any significant alteration in REM sleep. A treatment lasting 4 weeks provoked a reduction in dream recall and a significant "improvement" in dream content in depressed patients, in conjunction with remission of symptoms of depression $(52,53)$.

Note that in several studies that have used a sample of patients taking tricyclic or neuroleptic drugs in one single (often high) dose before bedtime, an increase in frightening dreams was consistently reported, but this effect was not observed when the dose was divided and administered over the course of the day $(54,55)$. 


\section{Selective Serotonin Reuptake Inhibitor Antidepressants}

Fluoxetine is one of the rare antidepressants that increase dream recall frequency $(44,56)$. This molecule tends to increase also nightmare recall (57) and the intensity of dreams reported (58, 59). When such intensification occurs in a negative context, it is nonetheless associated with improvements in symptoms of depression (60). Fluoxetine has also been incriminated in provoking episodes of RBD (61).

Paroxetine reduces the frequency of dream recall but increases intensity of dream content (memorability, visual intensity, quantity of sound, emotional intensity, and significance) both during treatment and also when suddenly withdrawn (62). It may also be responsible for activating RBD (63), while it would have a fairly positive effect on PTSD nightmares (64).

The action of fluvoxamine is very similar to that of paroxetine (62) with a reduction in dream recall and modification of dream intensity, but withdrawal results in an increase in both the strangeness of dreams and in the number of words used to report them.

Escitalopram was shown to increase dream recall frequency, in parallel with improvement of symptoms in depressed patients (65). Improvement of dream content was also reported: they are less complex and more intense at the emotional level. Citalopram also increased dream recall in a group of patients treated for obsessive compulsive disorder (66).

\section{Serotonin-Noradrenaline Reuptake Inhibitor Antidepressants}

Venlafaxine and its metabolite, desvenlafaxine, also tend to modify the dream content, with a large increase of "abnormal dreams" reported in desvenlafaxine withdrawal in depressed patients (67). With venlafaxine, an emergence of particularly realistic nightmares is observed (68) as well as episodes of RBD (69).

Duloxetine demonstrates effectiveness in reducing PTSD nightmares (70) and has a similar effect on sleep as venlafaxine (71): reduced length of REM sleep, fragmented sleep, and increase in periodic limb movement. For milnacipran, no increase in dream recall was observed (72).

\section{Other Antidepressants}

Mianserin is an antidepressant with a well-known sedative effect (24). It induces a reduction in dream recall according to Besançon et al. (56). Mirtazapine, which has similar properties, may be useful for treating PTSD nightmares (73) but was also reported to induce nightmares (74). Note that REM sleep is partially suppressed by mianserin intake whereas mirtazapine has nearly no impact on REM sleep (75).

Trazodone inhibits recapture of serotonin and blocks $5 \mathrm{HT}_{2 \mathrm{~A}}$ and $5 \mathrm{HT}_{2 \mathrm{C}}$ receptors $(76,77)$. It is widely used throughout the world as a treatment for insomnia. A withdrawal syndrome from trazodone induces a nightmare increase (78). During treatment, this molecule reduces nightmare in patients suffering from depression (79), PTSD (80), or cancer (81). Nefazodone (similar to trazodone) also inhibits recapture of norepinephrine $(82,83)$. It has little effect on REM sleep in depressed patients (84) and reduces dream recall frequency (44). Regarding dream content, five of the 18 parameters investigated showed a reduction (intensity, number of other people, presence of the body, sexual content, and number of scenes). Note that some authors observed an increase in REM sleep in healthy subjects taking nefazodone (85). This molecule seems to be also efficient for treating nightmares in PTSD patients (86).

Bupropion is a low-strength dopamine-norepinephrine reuptake inhibitor, and its effect on REM sleep is debated: some argue no effect (87), and others an increase (88). Often used as an adjuvant to SSRIs because it thwarts some of their side effects, it induces very few episodes of RBD (89) and increases dream recall frequency $(90,91)$. Regarding nightmares, only Balon (92) reported an increase in nightmare frequency in patients treated with bupropion.

Depressed patients taking tianeptine [which increases serotonin reuptake; $(93,94)]$ report increased insomnia complaints and nightmares (95). This molecule does not seem to significantly impact REM sleep (96).

Agomelatine is one of the more recent antidepressants on the market. It has an original profile: mainly melatoninergic agonist (MT1 and MT2) but also lightly $5 \mathrm{HT}_{2 \mathrm{C}}$ antagonist $(97,98)$. It does not influence REM sleep in depressed patients (99), nor in older healthy subjects (100). Regarding dreaming, a significant improvement in PTSD nightmares has been reported in one patient (101).

In summary, antidepressants generally tend to reduce dream recall frequency and to modify dream content, usually positively, in correlation with clinical improvements observed in patients. Most authors suggest that the reduction in dream recall frequency is mainly due to the inhibiting effect of these molecules on REM sleep. However, some antidepressants such as trimipramine do not reduce REM sleep but do reduce dream recall (52), and some such as clomipramine diminish REM sleep duration but have no effect on dream recall frequency (46), while others such as fluoxetine strongly inhibit REM sleep and increase dream recall frequency (24).

One may wonder which mechanism is at work since very different molecules with different modes of action have a relatively uniform impact on dream activity. What all these molecules have in common is the fact that they are antidepressants, and most of them improve the subjective perception of sleep [e.g., $(56,102)]$. This may account for the reduction in dream recall frequency and improved dream content tone. The "arousal-retrieval" model (16) proposing that intra-sleep awakenings are a key mechanism in the modulation of dream recall [supported by several experimental results; e.g., (19, 20)] support this hypothesis. In this framework, the reduction of intra-sleep awakenings explains the reduction of dream recall frequency engendered by antidepressants.

\section{EFFECTS OF ANTIPSYCHOTIC DRUGS ON DREAM RECALL}

First- or second-generation antipsychotic drugs are generally sedative and improve the continuity of sleep without significantly altering the internal structure of sleep (103). 
The effect of chlorpromazine (first antipsychotic on the market) on dreams recalled both after spontaneous awakenings in the morning and after nighttime awakenings in REM sleep showed that the length of nighttime dreams reported becomes quickly comparable with that obtained in the morning once the individual is in remission, while it is shorter when the individual is in the acute phase (104).

In healthy subjects, sulpiride does not significantly modify the structure of sleep. Dreams recalled in the morning are less clear and more emotionally neutral than in a control group. Awakenings in REM sleep result in shorter dream reports, less rich in aggressive or sexual content (105), which corroborates the findings of Karmer et al. (106) in schizophrenic patients treated with first-generation antipsychotics.

Lusignan et al. (107) focused on the characteristics of schizophrenic patients' dream reports, treated in chronic phase of the disorder using second-generation antipsychotic drugs (olanzapine, clozapine, quetiapine, or risperidone). Data obtained from questionnaires demonstrated that, under treatment, the group of schizophrenic patients reported more nightmares than healthy subjects, but no other between groups differences were observed for other parameters (number of dream recalls, recurrent dreams, and frequency of specific emotions). During nighttime awakenings in REM sleep, patients reported shorter dreams, but that aside, the parameters of dreams reported were comparable between the two groups, except for the presence of strangers in dreams, more frequently reported by patients.

Finally, a positive effect of olanzapine (108), risperidone (109), and aripiprazole (110) was observed on PTSD nightmares.

\section{EFFECTS OF ANXIOLYTIC AND HYPNOTIC DRUGS ON DREAM RECALL}

Although different in terms of their pharmacokinetics, benzodiazepines (which represent most of the anxiolytic and hypnotic drugs) are a fairly homogenous group of molecules. They all have sedative, anticonvulsant, muscle relaxing, and probably amnesic effects. Their impact is significant on the structure of sleep with, in particular, a drastic reduction in slow-wave sleep (in favor of N2) but only a low impact on REM sleep (111). They moreover reduce the number of intra-sleep awakenings, essentially in the initial 3-6 weeks of treatment.

TABLE 1 | Synthesis of the effects of psychotropic drugs on sleep and dreams according to the available data.

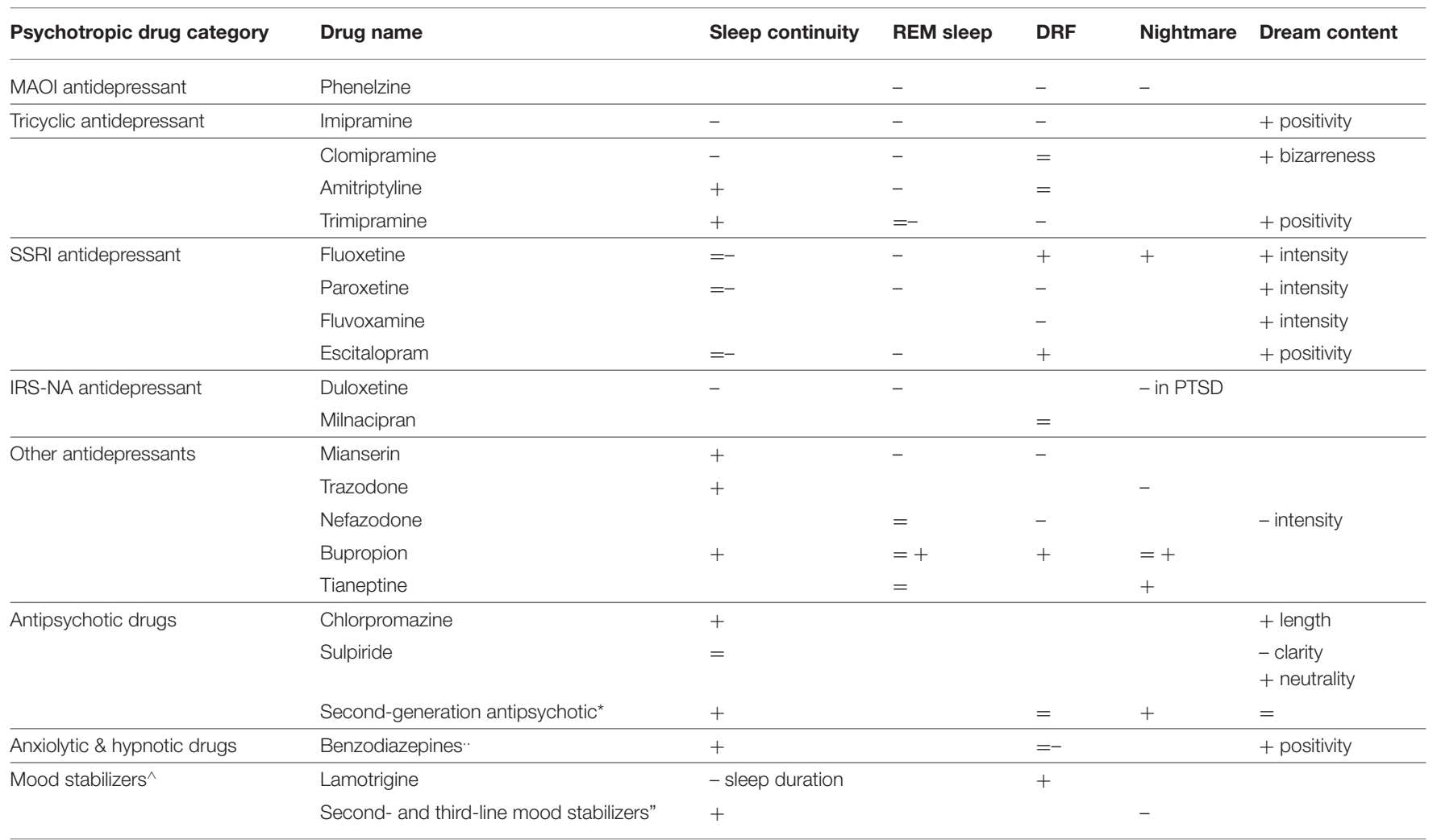

The review of Wichniak et al. (24) has been used to report the effects of antidepressant drugs on sleep continuity and REM sleep.

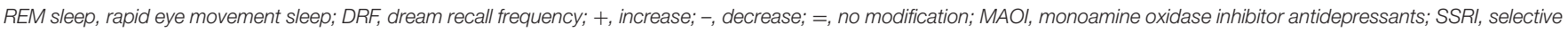

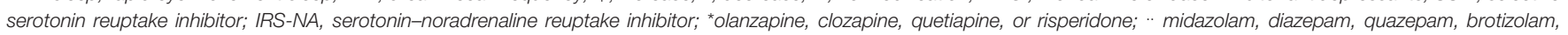

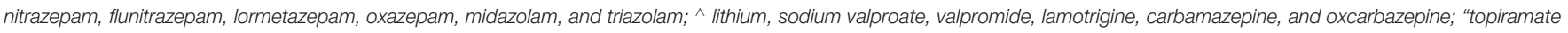
and gabapentin; PTSD, post-traumatic stress disorder. 
Clonazepam has probably been the most studied molecule in the field of sleep medicine, due to its numerous potential applications. It is notably often used for PTSD, even if the only study that explored the effect of clonazepam on this disorder reported inconclusive results (112).

Anesthetists have also explored the effects of various benzodiazepines in their field of expertise and, doing so, observed the recall of dreams at postanesthesia awakenings. When associated with ketamine or fentanyl, diazepam seems to reduce the number of dreams reported (113). Midazolam also reduces dream recall as compared with propofol (114). Finally, taking quazepam or brotizolam the night before a surgery reduces the number of dreams recalled while increasing the duration and quality of sleep (115).

According to the most well-controlled studies, most of these molecules seem to have little effect on dream recall frequency (116), particularly nitrazepam (117), and flunitrazepam (118). Regarding dream content, there is a tendency for an increased positive tone in insomniacs under treatment (116). However, in more clinical studies, a reduction in dream recall frequency is observed under lormetazepam (119) and oxazepam and midazolam (120) and a reduction of "anxious dreams" under diazepam and clorazepate dipotassium (121); and under oxazepam and midazolam, patients only remember pleasant dreams (120). Similarly, an improvement of "unpleasant dreams" is observed with triazolam and nitrazepam (122) associated with improvement of sleep quality.

Eszopiclone, a hypnotic drug derived from benzodiazepines, seems to stimulate the emergence of "abnormal dreams" upon withdrawal in a small number of older patients (123).

\section{EFFECT OF MOOD STABILIZERS ON DREAM RECALL}

To our knowledge, no studies directly explored parameters of dream activity for classic mood stabilizers, which are lithium, sodium valproate, valpromide, lamotrigine, carbamazepine, and oxcarbazepine.

In a geriatric sample, it has been reported that lamotrigine engenders an increase in dream recall frequency associated with a reduction in sleep duration in approximately $20 \%$ of patients, but this assessment is marginal (124).

\section{REFERENCES}

1. Pagel JF. Non-dreamers. Sleep Med. (2003) 4:23541. doi: 10.1016/S1389-9457(02)00255-1

2. Ruby P. Experimental research on dreaming: state of the art and neuropsychoanalytic perspectives. Front Psychol. (2011) 2:286. doi: 10.3389/fpsyg.2011.00286

3. Ruby PM. The neural correlates of dreaming have not been identified yet. Commentary on "The Neural Correlates of Dreaming. Nat Neurosci. 2017". Front Neurosci. (2020) 14:585470. doi: 10.3389/fnins.2020.585470

4. Pagel JF, Blagrove M, Levin R, States B, Stickgold B, White S. Definitions of dream: a paradigm for comparing field descriptive specific studies of dream. Dreaming. (2001) 11:195-202. doi: 10.1023/A:1012240307661
Topiramate and gabapentin, which are second- and third-line mood stabilizers, are also cited among therapeutic alternatives that can be used in the case of PTSD $(125,126)$. They induce a significant reduction of nightmares and improve sleep quality.

\section{CONCLUSION}

If we want to extract a general image of the impact of psychotropic drugs on dream recall given the available data, the short story is that the overriding majority of molecules engender a reduction in dream recall frequency once they improve the quality of sleep, or the concurrent psychiatric symptoms (Table 1). The few exacerbations of nightmares are caused by some molecules that perturb sleep and also by withdrawal from certain psychotropic drugs.

This makes sense in the framework of the "arousal-retrieval" model (16), stating that nighttime awakenings enable dreams to be encoded into long-term memory and therefore facilitate dream recall. It is thus coherent that molecules that improve sleep continuity by reducing intra-sleep awakenings consequently reduce dream recall frequency. Dream recall frequency is however under the control of several factors [e.g., (17); for a review, (2)], which certainly explain a large part of the variability of the results cited in this article. Some further studies allowing the direct correlation between dream recall and sleep variables in patients off and on psychotropic drugs are nonetheless necessary to confirm the general conclusion suggested by this review.

Regarding dream content, an often reported observation in depressed patients is a concomitant improvement of symptoms (improved mood during wake) and dream content (more positive dreams) after antidepressant intake. This observation fits well with both the continuity hypothesis of wake and dreaming cognition (127) and with the hypothesis of dreaming being involved in emotional regulation [e.g., (128)]. However, these correlational results cannot establish which and if an improvement impacts the other (improved mood causing improved dreams or the other way around), and further studies are needed to progress on this point.

\section{AUTHOR CONTRIBUTIONS}

AN and PR wrote the article. Both authors contributed to the article and approved the submitted version.

5. Windt JM, Nielsen T, Thompson E. Does consciousness disappear in dreamless sleep? Trends Cogn Sci. (2016) 20:87182. doi: 10.1016/j.tics.2016.09.006

6. Guénolé F, Nicolas A. Dreaming is a hypnic state of consciousness: Getting rid of the Goblot hypothesis and its modern avatars. Clin Neurophysiol. (2010) 40:193-9. doi: 10.1016/j.neucli.2010.04.001

7. Montangero J. Dreaming and REM-sleep: history of a scientific denial whose disappearance entailed a reconciliation of the neuroscience and the cognitive psychological approaches to dreaming. Int J Dream Res. (2018) 11:30-45.

8. Vallat R, Ruby PM. Is it a good idea to cultivate lucid dreaming? Front Psychol. (2019) 10:2585. doi: 10.3389/fpsyg.2019.02585

9. Foulkes D. Dream reports from different stages of sleep. J Abnorm Soc Psychol. (1962) 65:14-25. doi: 10.1037/h0040431 
10. Cavallero C, Cicogna P, Natale V, Occhionero M, Zito A. Slow wave sleep dreaming. Sleep. (1992) 15:562-6. doi: 10.1093/sleep/15.6.562

11. Solms M. Dreaming and REM sleep are controlled by different brain mechanisms. Behav Brain Sci. (2000) 23:84350. doi: 10.1017/S0140525X00003988

12. Nielsen TA. A review of mentation in REM and NREM sleep: "covert" REM sleep as a possible reconciliation of two opposing models. Behav Brain Sci. (2000) 23:851-66. doi: 10.1017/S0140525X0000399X

13. Pivik T, Foulkes D. NREM mentation: relation to personality, orientation time, and time of night. J Consult Clin Psychol. (1968) 32:144. doi: $10.1037 / \mathrm{h} 0025489$

14. Cicogna PC, Natale V, Occhionero M, Bosinelli M. A comparison of mental activity during sleep onset and morning awakening. Sleep. (1998) 21:46270. doi: 10.1093/sleep/21.5.462

15. Chellappa SL, Cajochen C. Ultradian and circadian modulation of dream recall: EEG correlates and age effects. Int J Psychophysiol. (2013) 89:16570. doi: 10.1016/j.ijpsycho.2013.03.006

16. Koulack D, Goodenough DR. Dream recall and dream recall failure: an arousal-retrieval model. Psychol Bull. (1976) 83:97584. doi: 10.1037/0033-2909.83.5.975

17. Schredl M, Wittmann L, Ciric P, Götz S. Factors of home dream recall: a structural equation model. J Sleep Res. (2003) 12:133-41. doi: 10.1046/j.1365-2869.2003.00344.x

18. De Gennaro L, Marzano C, Moroni F, Curcio G, Ferrara M, Cipolli C. Recovery sleep after sleep deprivation almost completely abolishes dream recall. Behav Brain Res. (2010) 206:293-8. doi: 10.1016/j.bbr.2009.09.030

19. Eichenlaub JB, Nicolas A, Daltrozzo J, Redouté J, Costes N, Ruby P. Resting brain activity varies with dream recall frequency between subjects. Neuropsychopharmacology. (2014) 39:1594-602. doi: 10.1038/npp.2014.6

20. Vallat R, Lajnef T, Eichenlaub JB, Berthomier C, Jerbi K, Morlet D, et al. Increased evoked potentials to arousing auditory stimuli during sleep: implication for the understanding of dream recall. Front Hum Neurosci. (2017) 11:132. doi: 10.3389/fnhum.2017.00132

21. Polini F, Principe R, Scarpelli S, Clementi F, De Gennaro L. Use of varenicline in smokeless tobacco cessation influences sleep quality and dream recall frequency but not dream affect. Sleep Med. (2017) 30:16. doi: 10.1016/j.sleep.2016.11.002

22. van Wyk M, Solms M, Lipinska G. Increased awakenings from non-rapid eye movement sleep explain differences in dream recall frequency in healthy individuals. Front Hum Neurosci. (2019) 13:370. doi: 10.3389/fnhum.2019.00370

23. Scarpelli S, D’Atri A, Bartolacci C, Gorgoni M, Mangiaruga A, Ferrara M, et al. Dream recall upon awakening from non-rapid eye movement sleep in older adults: electrophysiological pattern and qualitative features. Brain Sci. 10:343. doi: 10.3390/brainsci10060343

24. Wichniak A, Wierzbicka A, Walecka M, Jernajczyk W. Effect of antidepressant on sleep. Curr Psychiatr Rep. (2017) 19:63. doi: 10.1007/s11920-017-0816-4

25. Murphy MJ, Peterson MJ. Sleep disturbances in depression. Sleep Med Clin. (2015) 10:17-23. doi: 10.1016/j.jsmc.2014.11.009

26. Tribl GG, Wetter TC, Schredl M. Dreaming under antidepressants: a systematic review on evidence in depressive patients and healthy volunteers. Sleep Med Rev. (2013) 17:133-42. doi: 10.1016/j.smrv.2012.05.001

27. Schredl M. Traumerinnerung bei depressiven Patienten. Psychother. Psychosom. Medizinische Psychol. (1995) 45:414-7.

28. Bilici M, Yazici K, Özer ÖA, Kavakci Ö. Dream anxiety level in patients with major depression. Sleep Hypnosis. (2002) 4:15-21.

29. Palagini L, Rosenlicht N. Sleep, dreaming, and mental health: a review of historical and neurobiological perspectives. Sleep Med Rev. (2011) 15:17986. doi: 10.1016/j.smrv.2010.07.003

30. Cartwright RD, Young MA, Mercer P, Bears M. Role of REM sleep and dream variables in the prediction of remission from depression. Psychiatry Res. (1998) 80:249-55. doi: 10.1016/S0165-1781(98)00071-7

31. Gillin JC, Wyatt RJ, Fram D, Snyder F. The relationship between changes in REM sleep and clinical improvement in depressed patients treated with amitriptyline. Psychopharmacol. (1978) 59:267-72. doi: 10.1007/BF00426633

32. Wilt TJ, MacDonald R, Brasure M, Olson CM, Carlyle M, Fuchs E, et al. Pharmacologic treatment of insomnia disorder: an evidence report for a clinical practice guideline by the American college of physicians. Ann Intern Med. (2016) 165:103-12. doi: 10.7326/M15-1781

33. Sharpley AL, Cowen PJ. Effect of pharmacologic treatments on the sleep of depressed patients. Biol Psychiatr. (1995) 37:85-98. doi: 10.1016/0006-3223(94)00135-P

34. Vogel GW, Buffenstein A, Minter K, Hennessey A. Drug effects on REM sleep and on endogenous depression. Neurosci Biobehav Rev. (1990) 14:4963. doi: 10.1016/S0149-7634(05)80159-9

35. Thase ME. Depression, sleep, and antidepressants. J Clin Psychiatr. (1998) 59:55-65. doi: 10.1001/archpsyc.55.2.138

36. Landolt HP, Raimo EB, Schnierow BJ, Kelsoe JR, Rapaport MH, Gillin JC. Sleep and sleep electroencephalogram in depressed patients treated with phenelzine. Arch Gen Psychiatr. (2001) 58:268-76. doi: 10.1001/archpsyc.58.3.268

37. Lerer B, Bleich A, Kotler M, Garb R, Hertzberg M, Levin B. Posttraumatic stress disorder in Israeli combat veterans. effect of phenelzine treatment. Arch Gen Psychiatr. (1987) 44:976-81. doi: 10.1001/archpsyc.1987.01800230056010

38. Wyatt RJ, Fram DH, Kupfer DJ, Snyder F. Total prolonged drug-induced REM sleep suppression in anxious-depressed patients. Arch Gen Psychiatr. (1971) 24:145-55. doi: 10.1001/archpsyc.1971.01750080049007

39. Palladino A. Adverse reactions to abrupt discontinuation of phenelzine. J Clin Psychopharmacol. (1983) 3:2067. doi: 10.1097/00004714-198306000-00035

40. Akindele MO, Evans JI, Oswald I. Mono-amine oxidase inhibitors, sleep and mood. Electroencephalogr Clin Neurophysiol. (1970) 29:4756. doi: 10.1016/0013-4694(70)90078-7

41. Whitman RM, Pierce CM, Maas JW, Baldridge B. Drugs and dreams. II imipramine and prochlorperazine. Compr Psychiatr. (1961) 2:21926. doi: 10.1016/S0010-440X(61)80014-X

42. Oswald I, Lewis SA, Dunleavy DL, Brezinova V, Briggs M. Drugs of dependence though not of abuse: fenfluramine and imipramine. Br Med J. (1971) 3:70-3. doi: 10.1136/bmj.3.5766.70

43. Kramer M, Whitman RM, Baldridge B, Ornstein PH. Drugs and dreams 3. the effects of imipramine on the dreams of depressed patients. Am J Psychiatr. (1968) 124:1385-92. doi: 10.1176/ajp.124.10.1385

44. Armitage R, Rochlen A, Fitch T, Trivedi M, Rush AJ. Dream recall and major depression: a preliminary report. Dreaming. (1995) 5:18998. doi: 10.1037/h0094434

45. Dilsaver SC, Feinberg M, Greden JF. Antidepressant withdrawal symptoms treated with anticholinergic agents. Am J Psychiatr. (1983) 140:24951. doi: 10.1176/ajp.140.2.249

46. Tölle R, Crome A. Dream activation by thymoleptics. Arzneimittelforschung. (1970) 20:886-7.

47. Oudiette D, Dealberto MJ, Uguccioni G, Golmard JL, Merino-Andreu M, Tafti M, et al. Dreaming without REM sleep. Conscious Cogn. (2012) 21:1129-40. doi: 10.1016/j.concog.2012.04.010

48. Hoque R, Chesson AL. Pharmacologically induced/exacerbated restless legs syndrome, periodic limb movements of sleep, and REM behavior disorder/REM sleep without atonia: literature review, qualitative scoring, and comparative analysis. J Clin Sleep Med. (2010) 6:79-83. doi: $10.5664 /$ jcsm. 27716

49. Schenck CH, Mahowald MW. REM sleep behavior disorder: clinical, developmental, and neuroscience perspectives 16 years after its formal identification in sleep. Sleep. (2002) 25:120-38. doi: 10.1093/sleep/25. 2.120

50. Hartmann E, Cravens J. Long-term psychotropic drug administration: effects on dream content and dream density. Sleep Res. (1974) 3:119.

51. Bialos D, Giller E, Jatlow P, Docherty J, Harkness L. Recurrence of depression after discontinuation of long-term amitriptyline treatment. Am J Psychiatr. (1982) 139:325-9. doi: 10.1176/ajp.139.3.325

52. Riemann D, Löw H, Schredl M, Wiegand M, Dippel B, Berger M. Investigations of morning and laboratory dream recall and content in depressive patients during baseline conditions and under antidepressive treatment with trimipramine. Psychiatr J Univ Ott. (1990) 15:93-9.

53. Schredl M, Berger M, Riemann D. The effect of trimipramine on dream recall and dream emotions in depressive outpatients. Psychiatr Res. (2009) 167:279-86. doi: 10.1016/j.psychres.2008.03.002 
54. Flemenbaum A. Pavor nocturnus: a complication of single daily tricyclic or neuroleptic dosage. Am J Psychiatr. (1976) 133:570-2. doi: 10.1176/ajp.133.5.570

55. Strayhorn JM, Nash JL. Frightening dreams and dosage schedule of tricyclic and neuroleptic drugs. J Nerv Ment Dis. (1978) 166:878-e80. doi: 10.1097/00005053-197812000-00008

56. Besançon G, Cousin R, Guitton B, Lavergne F. Double-blind study of mianserin and fluoxetine in ambulatory therapy of depressed patients. Encephale. (1993) 19:341-5.

57. Lepkifker E, Dannon PN, Iancu I, Ziv R, Kotler M. Nightmares related to fluoxetine treatment. Clin Neuropharmacol. (1995) 18:904. doi: 10.1097/00002826-199502000-00013

58. Markowitz JC. Fluoxetine and dreaming. J Clin Psychiatr. (1991) 52:432.

59. Pace-Schott EF, Hobson JA, Stickgold R. The fluoxetine-mediated increase in NREM eye movements can be detected in the home setting using the Nightcap. Sleep Res. (1994) 23:459.

60. Balon R. Sexual obsessions associated with fluoxetine. J Clin Psychiatr. (1994) 55:496

61. Applebee GA, Attarian HP, Schenck CH. An angry bed partner. J Clin Sleep Med. (2009) 5:477-9. doi: 10.5664/jcsm.27606

62. Pace-Schott EF, Gersh T, Silvestri R, Stickgold R, Salzman C, Hobson JA. SSRI treatment suppresses dream recall frequency but increases subjective dream intensity in normal subjects. J Sleep Res. (2001) 10:12942. doi: 10.1046/j.1365-2869.2001.00249.x

63. Parish JM. Violent dreaming and antidepressant drugs: or how paroxetine made me dream that I was fighting Saddam Hussein. J Clin Sleep Med. (2007) 3:529-31.

64. Davidson JR. Treatment of posttraumatic stress disorder: the impact of paroxetine. Psychopharmacol Bull. (2003) 37(Suppl 1):76-88.

65. Quartini A, Anastasia A, Saverio Bersani F, Melcore C, Albano G, Colletti $\mathrm{C}$, et al. Changes in dream experience in relation with antidepressant escitalopram treatment in depressed female patients: a preliminary study. RicPsychiatr. (2014) 49:187-91. doi: 10.1708/1600.17460

66. Koponen H, Lepola U, Leiononen E, Jokinen R, Penttinen J, Turtonen J. Citalopram in the treatment of obsessive-compulsive disorder: an open pilot study. Acta Psychiatr Scand. (1997) 96:343-6. doi: 10.1111/j.1600-0447.1997.tb09927.x

67. Montgomery SA, Fava M, Padmanabhan SK, Guico-Pabia CJ, Tourian KA. Discontinuation symptoms and taper/poststudy-emergent adverse events with desvenlafaxine treatment for major depressive disorder. Int Clin Psychopharmacol. (2009) 24:296-305. doi: 10.1097/YIC.0b013e32832fbb5a

68. Zullino DF, Riquier F. Venlafaxine and vivid dreaming. J Clin Psychiatr. (2000) 61:600. doi: 10.4088/JCP.v61n0810a

69. Schuttle S. REM behavior disorder seen with venlafaxine (effexor). Sleep Res. (1996) 25:364.

70. Walderhaug E, Kasserman S, Aikins D, Vojvoda D, Nishimura C, Neumeister A. Effects of duloxetine in treatment-refractory men with posttraumatic stress disorder. Pharmacopsychiatry. (2010) 43:45-9. doi: 10.1055/s-0029-1237694

71. Boyle J, Eriksson ME, Gribble L, Gouni R, Johnsen S, Coppini DV, et al. Randomized, placebo-controlled comparison of amitriptyline, duloxetine, and pregabalin in patients with chronic diabetic peripheral neuropathic pain: impact on pain, polysomnographic sleep, daytime functioning, and quality of life. Diabetes Care. (2012) 35:2451-8. doi: 10.2337/dc12-0656

72. Lemoine $P$, Faivre T. Subjective and polysomnographic effects of milnacipran on sleep in depressed patients. Hum Psychopharmacol. (2004) 19:299303. doi: 10.1002/hup.600

73. Lewis JD. Mirtazapine for PTSD nightmares. Am J Psychiatry. (2002) 159:1948-9. doi: 10.1176/appi.ajp.159.11.1948-a

74. Dang A, Garg G, Rataboli PV. Mirtazapine induced nightmares in an adult male. Br J Clin Pharmacol. (2009) 67:1356. doi: 10.1111/j.1365-2125.2008.03305.x

75. Schmid DA, Wichniak A, Uhr $M$, Ising $M$, Brunner $H$, Held $K$, et al. Changes of Sleep architecture, spectral composition of sleep EEG, the nocturnal secretion of cortisol, ACTH, GH, prolactin, melatonin, ghrelin, and leptin, and the DEX-CRH test in depressed patients during treatment with mirtazapine. Neuropsychopharmacology. (2006) 31:83244. doi: 10.1038/sj.npp.1300923
76. Price LH, Charney DS, Heninger GR. Effects of trazodone treatment on alpha-2 adrenoceptor function in depressed patients. Psychopharmacology. (1986) 89:38-44. doi: 10.1007/BF00175186

77. Akbari V, Ghobadi S, Mohammadi S, Khodarahmi R. The antidepressant drug; trazodone inhibits Tau amyloidogenesis: prospects for prophylaxis and treatment of AD. Arch Biochem Biophys. (2020) 679:108218. doi: 10.1016/j.abb.2019.108218

78. Menza MA. Withdrawal syndrome in a depressed patient treated with trazodone. Am J Psychiatr. (1986) 143:1195. doi: 10.1176/ajp.143.9. $1195 \mathrm{a}$

79. Li TC, Su PY, Chiu HW, Peng CH. Trazodone ameliorates nightmares in major depressive disorder. J Neuropsychiatry Clin Neurosci. (2011) 23:E4. doi: 10.1176/appi.neuropsych.23.1.E4

80. Warner MD, Dorn MR, Peabody CA. Survey on the usefulness of trazodone in patients with PTSD with insomnia or nightmares. Pharmacopsychiatry. (2001) 34:128-31. doi: 10.1055/s-2001-15871

81. Tanimukai H, Murai T, Okazaki N, Matsuda Y, Okamoto Y, Kabeshita $\mathrm{Y}$, et al. An observational study of insomnia and nightmare treated with trazodone in patients with advanced cancer. Am J Hosp Palliat Care. (2013) 30:359-62. doi: 10.1177/1049909112452334

82. Owens MJ, Ieni JR, Knight DL, Winders K, Nemeroff CB. The serotonergic antidepressant nefazodone inhibits the serotonin transporter: in vivo and ex vivo studies. Life Sci. (1995) 57:L373-80. doi: 10.1016/0024-3205(95)02222-5

83. Davis R, Whittington R, Bryson HM. Nefazodone. a review of its pharmacology and clinical efficacy in the management of major depression. Drugs. (1997) 53:608-36. doi: 10.2165/00003495-199753040-00006

84. Wilson S, Argyropoulos S. Antidepressants and sleep: a qualitative review of the literature. Drugs. (2005) 65:92747. doi: 10.2165/00003495-200565070-00003

85. Ware JC, Rose FV, McBrayer RH. The acute effects of nefazodone, trazodone and buspirone on sleep and sleep-related penile tumescence in normal subjects. Sleep. (1994) 17:544-50. doi: 10.1093/sleep/17.6.544

86. Neylan TC, Lenoci M, Maglione ML, Rosenlicht NZ, Leykin Y, Metzler TJ, et al. The effect of nefazodone on subjective and objective sleep quality in posttraumatic stress disorder. J Clin Psychiatr. (2003) 64:44550. doi: 10.4088/JCP.v64n0415

87. Ott GE, Rao U, Lin KM, Gertsik L, Poland RE. Effect of treatment with bupropion on EEG sleep: relationship to antidepressant response. Int J Neuropsychopharmacol. (2004) 7:275-81. doi: 10.1017/S1461145704004298

88. Nofzinger EA, Reynolds CFIII, Thase ME, Frank E, Jennings JR, Fasiczka AL, et al. REM sleep enhancement by bupropion in depressed men. Am J Psychiatr. (1995) 152:274-6. doi: 10.1176/ajp.152.2.274

89. Lam SP, Zhang J, Tsoh J, Li SX, Ho CK, Mok V, et al. REM sleep behavior disorder in psychiatric populations. J Clin Psychiatr. (2010) 71:11013. doi: 10.4088/JCP.105877gry

90. Becker RE, Dufresne RL. Perceptual changes with bupropion, a novel antidepressant. Am J Psychiatr. (1982) 139:12001. doi: 10.1176/ajp.139.9.1200

91. Posner J, Bye A, Dean K, Peck AW, Whiteman PD. The disposition of bupropion and its metabolites in healthy male volunteers after single and multiple doses. Eur J Clin Pharmacol. (1985) 29:97-103. doi: 10.1007/BF00547376

92. Balon R. Bupropion and nightmares. Am J Psychiatr. (1996) 153:57980. doi: 10.1176/ajp.153.4.579b

93. McEwen BS, Chattarji S, Diamond DM, Jay TM, Reagan LP, Svenningsson $\mathrm{P}$, et al. The neurobiological properties of tianeptine (Stablon): from monoamine hypothesis to glutamatergic modulation. Mol Psychiatr. (2010) 15:237-49. doi: 10.1038/mp.2009.80

94. Cooper CM, Whiting DA, Cowen PJ, Harmer CJ. Tianeptine in an experimental medicine model of antidepressant action. J Psychopharmacol. (2015) 29:582-90. doi: 10.1177/0269881115573810

95. Guelfi JD, Pichot P, Dreyfus JF. Efficacy of tianeptine in anxious-depressed patients: results of a controlled multicenter trial versus amitriptyline. Neuropsychobiology. (1989) 22:41-8. doi: 10.1159/000118590

96. Murck H, Nickel T, Künzel H, Antonijevic IA, Schill J, Zobel A, et al. State markers of depression in sleep EEG: dependency on drug and gender in patients treated with tianeptine or paroxetine. Neuropsychopharmacology. (2003) 28:348-58. doi: 10.1038/sj.npp.1300029 
97. Srinivasan V, Zakaria R, Othman Z, Lauterbach EC, AcuñaCastroviejo D. Agomelatine in depressive disorders: its novel mechanisms of action. J Neuropsychiatr Clin Neurosci. (2012) 24:290-308. doi: 10.1176/appi.neuropsych.11090216

98. Konstantakopoulos G, Dimitrakopoulos S, Michalopoulou PG. The preclinical discovery and development of agomelatine for the treatment of depression. Expert Opin Drug Discov. (2020) 15:1121-32. doi: 10.1080/17460441.2020.1781087

99. Quera-Salva MA, Lemoine P, Guilleminault C. Impact of the novel antidepressant agomelatine on disturbed sleep-wake cycles in depressed patients. Hum Psychopharmacol. (2010) 2:222-9. doi: 10.1002/hup.1112

100. Leproult R, Van Onderbergen A, L'Hermite-Baleriaux M, van Cauter E, Copinschi G. Phase-shifts of 24-h rhythms of hormonal release and body temperature following early evening administration of the melatonin agonist agomelatine in healthy older men. Clin Endocrinol. (2005) 63:298304. doi: 10.1111/j.1365-2265.2005.02341.x

101. De Berardis D, Serroni N, Marini S, Moschetta FS, Martinotti G, Di Giannantonio M. Agomelatine for the treatment of posttraumatic stress disorder: a case report. Ann Clin Psychiatr. (2012) 24:2412. doi: $10.1155 / 2012 / 642752$

102. Dujardin S, Pijpers A, Pevernagie D. Prescription drugs used in Insomnia. Sleep Med Clin. (2020) 15:133-45. doi: 10.1016/j.jsmc.2020.02.002

103. Monti JM, Monti D. Sleep in schizophrenic patients and the effects of antipsychotic drugs. Sleep Med Rev. (2004) 8:133-48. doi: 10.1016/S1087-0792(02)00158-2

104. Ornstein PH, Whitman RM, Kramer M, Baldridge BJ. Drugs and dreams. IV. tranquilizers and their effects upon dreams and dreaming in schizophrenic patients. Exp Med Surg. (1969) 27:145-56.

105. Gaillard JM, Moneme A. Modification of dream content after preferential blockade of mesolimbic and mesocortical dopaminergic systems. J Psychiatr Res. (1977) 13:247-56. doi: 10.1016/S0022-3956(77)90020-6

106. Kramer M, Whitman RM, Baldridge BJ, Ornstein PH. Dream content in male schizophrenic patients. Dis Nerv Syst. (1970) 31:51-8.

107. Lusignan FA, Zadra A, Dubuc MJ, Daoust AM, Mottard JP, Godbout R. Dream content in chronically-treated persons with schizophrenia. Schizophr Res. (2009) 112:164-73. doi: 10.1016/j.schres.2009.03.032

108. Jakovljevic M, Sagud M, Mihaljevic-Peles A. Olanzapine in the treatmentresistant, combat-related PTSD - a series of case reports. Acta Psychiat Scand. (2003) 107:394-6. doi: 10.1034/j.1600-0447.2003.00065.x

109. David D, De Faria L, Mellman TA. Adjunctive risperidone treatment and sleep symptoms in combat veterans with chronic PTSD. Depress Anxiety. (2006) 23:489-91. doi: 10.1002/da.20187

110. Lambert MT. Aripiprazole in the management of post-traumatic stress disorder symptoms in returning Global war on Terrorism victims. Int Clin Psychopharmacol. (2006) 21:185-7. doi: 10.1097/01.yic.0000185021.48279.00

111. Borbely A. (1987). Das Geheimnis des Schlafs. dtv Sachbuch, Stuttgart.

112. Cates M, Bishop M, Davis L, Lowe J, Wooley T. Clonzaepam for treatment of sleep disturbances associated with combat-related posttraumatic stress disorder. Ann Pharmacother. (2004) 38:1395-9. doi: 10.1345/aph.1E043

113. Grace RF. The effect of variable-dose diazepam on dreaming and emergence phenomena in 400 cases of ketamine-fentanyl anaesthesia. Anaesthesia. (2003) 58:904-10. doi: 10.1046/j.1365-2044.2003.03341.x

114. Stait ML, Leslie K, Bailey R. Dreaming and recall during sedation for colonoscopy. Anaesth Intensive Care. (2008) 36:685-90. doi: 10.1177/0310057X0803600509
115. Nishiyama T, Yamashita K, Yokoyama T, Imoto A, Manabe M. Effects of quazepam as a preoperative night hypnotic: comparison with brotizolam. $J$ Anesth. (2007) 21:7-12. doi: 10.1007/s00540-006-0445-2

116. Schredl M, Schäfer G, Weber B, Heuser I. Dreaming and insomnia: dream recall and dream content of patients with insomnia. J Sleep Res. (1998) 7:191-8. doi: 10.1046/j.1365-2869.1998.00113.x

117. Firth H. Sleeping pills and dream content. Br J Psychiatr. (1974) 124:54753. doi: 10.1192/bjp.124.6.547

118. Gaillard JM, Phelippeau M. Benzodiazepine-induced modifications of dream content: the effect of flunitrazepam. Neuropsychobiology. (1976) 2:3744. doi: 10.1159/000117527

119. Oswald I, French C, Adam K, Gilham J. Benzodiazepine hypnotics remain effective for 24 weeks. $\mathrm{Br}$ Med J. (1982) 284:860-3. doi: 10.1136/bmj.284.6319.860

120. Fischbach R. Hypnotic efficacy and safety of midazolam and oxazepam in hospitalized female patients. Br J Clin Pharmacol. (1983) 16:157S-160S. doi: 10.1111/j.1365-2125.1983.tb02288.x

121. Allen RM. Attenuation of drug-induced anxiety dreams and pavor nocturnus by benzodiazepines. J Clin Psychiatr. (1983) 44:106-8.

122. Ellingsen PA. Double-blind trial of triazolam $0.5 \mathrm{mg}$ vs. nitrazepam $5 \mathrm{mg}$ in outpatients. Acta Psychiatr Scand. (1983) 67:154-8. doi: 10.1111/j.1600-0447.1983.tb00336.x

123. Zammit GK, McNabb LJ, Caron J. Efficacy and safety of eszopiclone across 6-weeks of treatment for primary insomnia. Curr Med Res Opin. (2004) 20:1979-91. doi: 10.1185/174234304X15174

124. Sajatovic M, Gildengers A, Al Jurdi RK, Gyulai L, Cassidy KA, Greenberg $\mathrm{RL}$, et al. Multisite, open-label, prospective trial of lamotrigine for geriatric bipolar depression: a preliminary report. Bipolar Disord. (2011) 13:294302. doi: 10.1111/j.1399-5618.2011.00923.x

125. Berlant J, van Kammen D. Open-label topiramate as primary or adjunctive therapy in chronic civilian posttraumatic stress disorder; a preliminary report. J Clin Psychiatr. (2002) 63:15-20. doi: 10.4088/JCP. v63n0104

126. Hamner MB, Brodrick PS, Labbate LA. Gabapentin in PTSD: a retrospective, clinical series of adjunctive therapy. Ann Clin Psychiatr. (2001) 13:1416. doi: 10.3109/10401230109148960

127. Schredl M, Hofmann F. Continuity between waking activities and dream activities. Conscious Cogn. (2003) 12:298308. doi: 10.1016/S1053-8100(02)00072-7

128. Vallat $R$, Chatard $B$, Blagrove $M$, Ruby $P$. Characteristics of the memory sources of dreams: a new version of the contentmatching paradigm to take mundane and remote memories into account. PLoS ONE. (2017)12:e0185262. doi: 10.1371/journal.pone. 0185262

Conflict of Interest: The authors declare that the research was conducted in the absence of any commercial or financial relationships that could be construed as a potential conflict of interest.

Copyright (c) 2020 Nicolas and Ruby. This is an open-access article distributed under the terms of the Creative Commons Attribution License (CC BY). The use, distribution or reproduction in other forums is permitted, provided the original author(s) and the copyright owner(s) are credited and that the original publication in this journal is cited, in accordance with accepted academic practice. No use, distribution or reproduction is permitted which does not comply with these terms. 